Diabetologia (1994) 37: 91-94

\title{
A high weight gain early in life is associated with an increased risk of Type 1 (insulin-dependent) diabetes mellitus
}

\author{
C.Johansson ${ }^{1}$, U.Samuelsson ${ }^{1}$, J. Ludvigsson ${ }^{2}$ \\ ${ }^{1}$ Department of Paediatrics, Ryhov Hospital, Jönköping, Sweden \\ ${ }^{2}$ Department of Paediatrics, Faculty of Health Sciences, University Hospital, Linköping, Sweden
}

Summary Growth during the first years of life in relation to type of feeding in infancy was retrospectively studied in an unselected population-based group of 297 children who had been diagnosed with Type 1 (insulin-dependent) diabetes mellitus before the age of 15 years (probands) and 792 individually-matched referent subjects. Reliable data were collected from child welfare clinics. Probands weighed slightly less at birth but their weight gain at $6,9,18$ and 30 months of age was significantly greater $(p<0.02)$ than that of referent children. The weight gain of children who had never been breast-fed was more marked than that of breast-fed children; this was found for both probands and referent children. But also among exclusively breast-fed children ( $>2$ months), probands gained significantly more in weight from birth up to 18 and 30 months of age than exclusively breast-fed referent children. Early weight gain appears to be a risk factor for development of Type 1 diabetes. The lower weight gain in breast-fed compared to non-breast-fed children may explain the protective effect of breast feeding against Type 1 diabetes observed in several studies. [Diabetologia (1994) 37:91-94]

Key words Type 1 (insulin-dependent) diabetes mellitus, aetiology, early growth, breast feeding.
There is a close connection between insulin secretion and growth in children [1] as an adequate insulin supply is needed for normal growth. Insulin seems to have both a direct effect and an indirect effect via insulinlike growth factors [2].

There have been numerous studies regarding growth in children at the time of and after the clinical onset of Type 1 (insulin-dependent) diabetes mellitus [3-7]. It is well known that growth is seriously impaired in Type 1 diabetic patients with very poor metabolic control [8]. In patients with reasonably good metabolic control varying results in growth after onset of Type 1 diabetes have been observed [3-5, 9].

A few studies have investigated growth during the first years of life in children who later develop Type 1

Received: 15 April 1993

and in revised form: 30 July 1993

Corresponding author: Professor J.Ludvigsson, Department of Paediatrics, Faculty of Health Sciences, University Hospital, S-581 85 Linköping, Sweden diabetes. Baum et al. [10] compared diabetic and nondiabetic children regarding weight gain during the first year of life and found that children who develop Type 1 diabetes are heavier at certain stages in infancy. Blom et al. [11] concluded from an incident case referent study that children (especially boys) who later develop diabetes tend to be slightly but consistently taller, although not heavier, than matched referent children from early childhood up to the year of clinical onset of Type 1 diabetes.

Breast-feeding has in some studies been shown to have a protective role in development in Type 1 diabetes $[12,13]$ while other studies have failed to confirm this result $[14,15]$. A previous study [16] based on the same material as in this study, did not show any significant difference in the duration of exclusive breastfeeding between diabetic patients and control children apart from differences in some subgroups. For instance, diabetic children born to mothers over 32 years of age were breast-fed for a shorter time than control children. Virtanen et al. [12] found that both a short duration of breast-feeding and an early introduction of 
Table 1. Weight gain (expressed as change in SD scores) from birth to given ages

\begin{tabular}{|c|c|c|c|c|c|}
\hline & $\begin{array}{c}\text { Diabetic children } \\
95 \% \mathrm{CI}\end{array}$ & $\begin{array}{c}\text { Referent children } \\
95 \% \text { CI }\end{array}$ & $p$ value & $\begin{array}{l}95 \% \text { CI Mean } \\
\text { difference }\end{array}$ & $\begin{array}{l}\text { Approx. weight } \\
\text { diff. in grammes }\end{array}$ \\
\hline Birth -3 months & $0.390 .27-0.51$ & $0.29 \quad 0.21-0.38$ & 0.160 & $-0.040-0.242$ & 80 \\
\hline Birth -6 months & $0.49 \quad 0.35-0.62$ & $0.29 \quad 0.21-0.39$ & 0.017 & $0.035-0.353$ & 200 \\
\hline Birth -18 months & $0.57 \quad 0.42-0.71$ & $0.33 \quad 0.22-0.43$ & 0.012 & $0.054-0.428$ & 350 \\
\hline Birth -30 months & $0.58 \quad 0.41-0.74$ & $\begin{array}{lll}0.30 & 0.17-0.42\end{array}$ & 0.010 & $0.069-0.495$ & 500 \\
\hline
\end{tabular}

Confidence interval (CI) above zero indicates a statistically significant difference between the sample means

dairy products were associated with an increased risk of developing Type 1 diabetes. Cow's milk protein (bovine serum albumin) has been suggested as a possible trigger for development of Type 1 diabetes and antibodies to cow's milk protein have been found in newlydiagnosed diabetic patients [17]. However, children who are exclusively breast-fed do not only avoid cow's milk protein but have a lower energy intake than those who are exclusively bottle-fed from birth [18]. The lower energy intake results in a lower growth rate from 3 months of age $[19,20]$. An increased intake of food increases the demand for insulin. A high insulin secretion may increase antigen presentation of the beta cells [2123] possibly leading to a risk for later autoimmune destruction and development of Type 1 diabetes in predisposed individuals. Thus, the slightly protective effect of breast-feeding against Type 1 diabetes seen in some studies might depend on its effect on energy intake and growth. We therefore decided to look further into growth during the first years of life in a large cohort of children with Type 1 diabetes, to study the possible effect of breast-feeding on growth and to investigate if difference in growth or type of feeding might influence the tendency to develop Type 1 diabetes.

\section{Subjects and methods}

From five paediatric departments in the southeast region of Sweden 329 diabetic children with age at onset of diabetes ( = first insulin injection) less than 15 years, diagnosed between 1974 and 1988 were invited to participate in the study. This includes all the diabetic patients treated at the paediatric departments at the time for the study. Of 329 patients $297(90 \%)$ agreed to participate. For each diabetic child three control children matched for age (year of birth), sex and geographical region were selected. The matching was done on an individual basis. The control children were traced through the official Swedish population register. Of 977 non-diabetic children who were invited to participate $792(81 \%)$ accepted. None of the patients or control subjects were siblings. After informed consent was obtained from the parents copies of files regarding growth and infant feeding habits were retrieved from child welfare clinics. A good correlation between recorded data and information from the parents regarding feeding habits has been shown earlier [16]. Height and weight measurements have been read as standard deviation (SD) from growth charts used at all Swedish welfare clinics and approximated to the nearest $0.5 \mathrm{SD}$ line of 3 , $6,9,18$ and 30 months of age. Weight and height in $\mathrm{kg}$ and $\mathrm{cm}$ could not be used as the children were not weighed and measured at exactly 3, 6, 9 etc months of age. Approximate figures in grammes are shown in Table 1 to explain what the SD difference corresponds to.

The number of weight/height observations up to 30 months of age was 1,625 for the probands and 4,090 for the control children. The total number of weight/height observations was 5,715 .

\section{Statistical analysis}

The results were analysed by a two-tailed Student's $t$ test. $95 \%$ confidence intervals were calculated according to the methods described by Gardner and Altman [24]. Differences were considered significant at $p<0.05$. When there were indications of skewed distribution we also used Mann-Whitney U-test.

\section{Results}

The probands who later got diabetes weighted slightly less at birth compared to referent children $(-0.16 \mathrm{SD}$ vs $-0.05 \mathrm{SD}$, respectively, $p=0.09, t$-test).

The weight gain for probands and referent children expressed as change in SD score from birth to 30 months of age is presented in Table 1 . The weight gain from birth to 30 months of age was significantly greater in probands than in referent children $(p<0.02)$. The difference in weight gain was noted in the first interval, from birth to 3 months of age and was statistically significant at all other age intervals (Table 1). The difference in weight gain between probands and referent children up to 18 and 30 months of age was more marked in girls $(0.54 \mathrm{SD}$ vs $0.21 \mathrm{SD}$ and $0.56 \mathrm{SD}$ vs $0.14 \mathrm{SD}$, respectively, $p<0.05, t$-test) than in boys $(0.60 \mathrm{SD}$ vs $0.44 \mathrm{SD}$ and $0.60 \mathrm{SD}$ vs $0.44 \mathrm{SD}$, respectively, NS). Probands born to mothers over 32 years of age gained more in weight up to 18 and 30 months of age compared to referent children born to mothers over 32 years ( $0.63 \mathrm{SD}$ and $0.79 \mathrm{SD}$ for probands, 0.10 and -0.02 SD for referent children, $p<$ 0.01 and $p<0.005, t$-test).

The weight gain in children who had never been breast-fed $(10 \%$ of all probands and $11 \%$ of all control children) was more marked than in the breast-fed children (Fig. 1). Probands who had never been breastfed gained significantly more in weight from birth to 6 and 9 months of age than probands who had been 
breast-fed. Referent children who had never been breast-fed gained significantly more from birth to 9 months of age than referent children who had been breast-fed (Fig. 1).

No difference in weight gain was found from birth to 18 and 30 months of age between probands and referent children who were exclusively breast-fed ( = age before introducting cow's milk containing formulas) for only 2 months. However, among children who were exclusively breast-fed for a longer time, those who later developed diabetes (the probands) gained more weight than referent children (Fig. 2) $(p<0.05, t$-test for 3 and 5 months exclusive breast-feeding).

Children with onset of diabetes at $0-4$ years of age weighed significantly less at birth $(n=88,-0.43 \mathrm{SD})$ than those with onset at $5-9(n=132,-0.03 \mathrm{SD})$ and $10-15(n=77,-0.05 \mathrm{SD})$ years of age $(p<0.03, p<$ $0.05, t$-test, respectively).

There was a trend ( $p=0.1, t$-test) towards a greater weight gain in children who developed diabetes at the age of $0-4$ years compared to those who developed diabetes at 5-9 and $10-15$ years of age. When studying children who had never been breast-fed this trend became significant: children who developed diabetes at $0-4$ years of age had gained 1.13 SD from birth to 30 months of age compared to 0.22 SD for children diagnosed at $10-15$ years of age $(p<0.02$, Mann-Whitney $\mathrm{U}$-test); difference in weight gain approximately $1.13 \mathrm{~kg}$.

There was no difference in height at birth between probands and referent children ( $-0.19 \mathrm{SD}$ vs -0.16 SD, respectively). Probands were slightly taller than referent children at 18 months of age but no differences were seen at 3,6,9 and 30 months of age.

\section{Discussion}

The Swedish medical system provides treatment at a paediatric department for all children diagnosed with diabetes up to 15 years of age. As a great majority of both patients and referent children chose to participate we know that the group studied is representative for the population of the region.

The duration of breast-feeding has increased over the study period but there was no significant difference between duration of breast-feeding at any time between diabetic patients and control children [16].

Almost all children in Sweden regularly attend child welfare clinics. The child is usually seen by the same nurse during the preschool years. Weight (without clothing) in kilogrammes and height in centimeters is plotted by the nurse on growth charts which are the same for all patients in the study. Thus, it can be assumed that the consistency in measurements and recordings was adequate during the study period. Furthermore, local inconsistencies would obscure the picture rather than causing certain trends. Both pro-

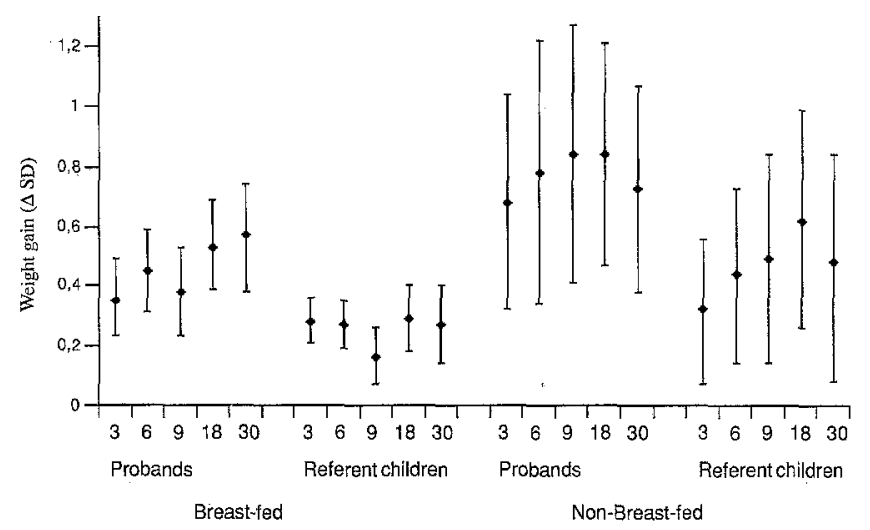

Fig.1. Weight gain expressed as change in SD score ( $\Delta \mathrm{SD})$ from birth to $3,6,9,18$ and 30 months of age in probands and referent children, who were either breast-fed or never breast-fed. Mean and $95 \%$ confidence intervals

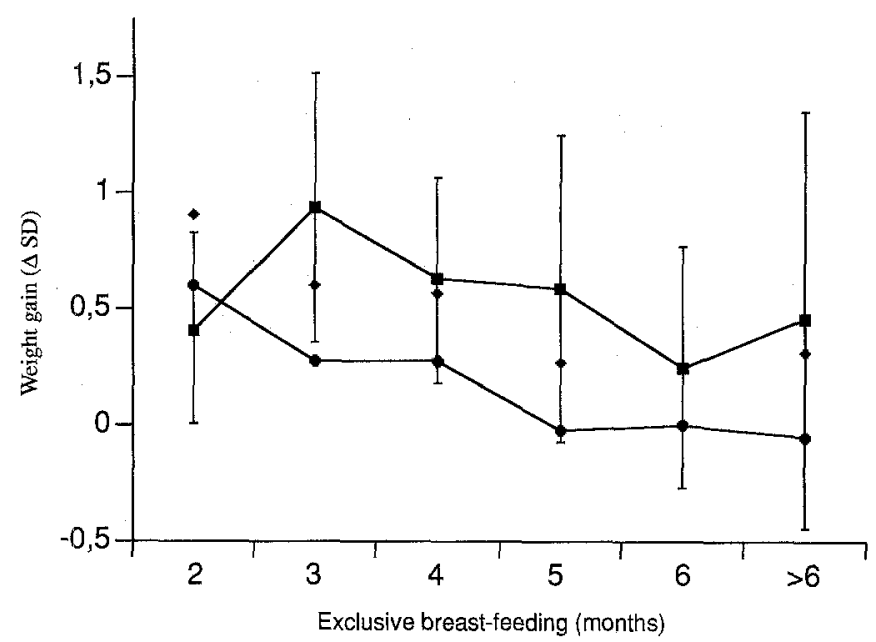

Fig.2. Weight gain expressed as change in SD score $(\Delta \mathrm{SD})$ from birth to 18 months of age for probands $\mathbf{a n d}$ referent children

- who have been exclusively breast-fed for 2 to more than 6 months. Mean and $95 \%$ confidence interval (CI). Indicates upper $95 \%$ CI for referent children

bands and referent children almost consistently fell above the norm for the growth chart indicating a possible secular trend. This does not interfere with our comparisons.

Probands had gained more in weight than referent children during their first years of life. The difference was seen at 3 months of age and was statistically significant at $6,9,18$ and 30 months. Similar results were seen in the study by Baum et al. [10] while our findings are somewhat different from those of Blom et al. [11] who did not show any difference in weight for age between diabetic and referent children from birth to clinical onset of Type 1 diabetes. They found however that boys who developed diabetes were consistently taller than referent boys from birth. In this study there were no significant differences in height gain between probands and referent children from birth up to $3,6,9,18$ or 30 months. 
Exposure to cow's milk protein early in life has been suggested as a possible cause of Type 1 diabetes [17]. The more marked weight gain in non-breast-fed children could be of less importance than being exposed to cow's milk protein. However, even exclusively breastfed children who later developed Type 1 diabetes gained more weight than exclusively breast-fed referent children.

A bold speculation to explain our findings could be that "over-feeding" causes an increased demand for insulin which may result in an increased beta-cell antigen presentation [22]. If this occurs during a critical period early in life it might contribute to autoimmune reactions when the same antigen presents later in life in individuals predisposed to Type 1 diabetes. Metabolically active beta cells have been shown to be more susceptible to cytokine (IL-1 $\beta$ ) damage than the resting beta cell [25]. This together with our results would be consistent with the tendency to develop Type 1 diabetes during periods of increased insulin demand.

In conclusion it appears that early weight-gain itself correlates more with the development of Type 1 diabetes than breast-feeding or non-breast-feeding or even early exposure to cow's milk protein. The lower weight-gain in breast-fed compared to non-breast-fed children may be the protective effect that breast-feeding has against development of diabetes which has been seen in several studies.

Acknowledgement. This study was supported by a grant from Barndiabetesfonden (The Swedish Child Diabetes Foundation).

\section{References}

1. Berger M, Berchthold $P$ (1985) Insulin as growth factor. In: Marble A, Krall LP, Bradley RF, Christlieb AR (eds) Joslin's diabetes mellitus. Lea and Febiger, Philadelphia, pp 101-102

2. Hill DJ, Milner RD (1985) Insulin as a growth factor. Paediat Res 19: 879-886

3. Hjelt K, Braendholt V, Kamper J, Vestermark S (1983) Growth in children with diabetes mellitus. Dan Med Bull 30: 28-33

4. Herber SM, Dunsmore IR (1988) Does control affect growth in diabetes mellitus. Acta Ped Scand 77: 303-305

5. Salardi S, Tonioli S, Tassoni P, Tellarini M, Mazzanti L, Cacciari E (1987) Growth and growth factors in diabetes mellitus. Arch Dis Child 62: 57-62

6. Songer TJ, LaPorte R, Tajima N et al. (1986) Height at diagnosis of insulin dependent diabetes in patients and their nondiabetic family members. BMJ 292: 1419-1422
7. Hoskins PJ, Leslie RDG, Pyke DA (1985) Height at diagnosis of diabetes in children: a study in identical twins. BMJ 290: $278-280$

8. Guest CM (1953) The Mauriac syndrome: dwarfism, hepatomegaly and obesity with juvenile diabetes mellitus. Diabetes 2: $415-417$

9. Jivani SKM, Rayner PHW (1973) Does control influence the growth of diabetic children? Arch Dis Child 48: 109-115

10. Baum JD, Ounsted M, Smith MA (1975) Weight gain in infancy and subsequent development of diabetes mellitus in childhood. Lancet I: 866 (Letter)

11. Blom L, Persson LA, Dahlqvist G (1992) A high linear growth is associated with an increased risk of childhood diabetes mellitus. Diabetologia 35: 528-533

12. Virtanen SM, Räsenen L, Aro A et al. (1991) Infant feeding in Finnish children $<7$ years of age with newly diagnosed IDDM. Diabetes Care 14: 415-417

13. Mayer EJ, Hamman RF, Gay EL, Lezotte DC, Savitz DA, Klingensmith GJ (1988) Reduced risk of IDDM among breastfed children: the Colorado IDDM registry. Diabetes 37: 1625-1632

14. Fort P, Lanes R, Dahlem S (1986) Breast-feeding and insulindependent diabetes mellitus in children. $J$ Am Coll Nutr 5: 439-441

15. Nigro G, Campea L, De Novellis A and Orsini M (1985) Breast-feeding and insulin-dependent diabetes. Lancet I: 467 (Letter)

16. Samuelsson U, Johansson C, Ludvigsson J (1993) Breastfeeding plays a marginal, if any, role in the prevention of insulin dependent diabetes mellitus (IDDM). Diab Res Clin Pract 19: 203-210

17. Karjalainen J, Martin J, Knip M et al. (1992) A bovine albumin peptide as a possible trigger of insulin-dependent diabetes mellitus. N Engl J Med 327: 302-330

18. Axelsson I, Borulf S, Righard L, Räihä N (1987) Protein and energy intake during weaning: 1 . Effects on growth. Acta Ped Scand 76:321-327

19. Fomon SJ, Thomas LN, Filer LJ, Ziegler EE, Leonard MT (1971) Food consumption and growth of normal infants fed milk-based formulas. Acta Ped Scand Suppl 223: 3-36

20. Hithcock NE, Gracey M, Gilmour AI (1985) The growth of breast fed and artificially fed infants from birth to twelve months. Acta Ped Scand 74: 240-245

21. Kämpe O, Andersson A, Björk E, Hallberg A, Karlsson FA (1989) High glucose stimulation of 64,000-Mr islet cell autoantigen expression. Diabetes 38: 1326-1328

22. Björk E, Kämpe O, Andersson A, Karlsson FA (1992) Expression of the $64 \mathrm{kDa} / g$ lutamic acid decarboxylase rat islet cell antigen is influenced by the rate of insulin secretion. Diabetologia 32: 490-493

23. Björk E, Kämpe O, Karlsson FA et al. (1992) Glucose regulation of the autoantigen GAD 65 in human pancreatic islets. J Clin Endocrinol Metab 75: 1574-1576

24. Gardner MJ, Altman DG (1989) Statistics with confidence confidence intervals and statistical guidelines. BMJ London

25. Palmer JP, Helqvist S, Giatgen A et al. (1989) Interaction of $\beta$-cell activity and IL- 1 concentration and exposure time in isolated rat islets of Langerhans. Diabetes 38: 1211-1216 